\title{
Desigualdad de GÉNero y MUerte de niños en Ocotepec, Chiapas
}

\author{
Gender Inequality and Children Death in Ocotepec, Chiapas
}

\author{
Renata Gabriela Cortez-Gómez
}

Resumen: El objetivo de este artículo es analizar cómo la desigualdad de género afecta las trayectorias de atención de niños menores de cinco años que fallecieron por causas prevenibles en el periodo 2005-2010 en Ocotepec, Chiapas. Se emplea un enfoque de género constructivistarelacional para demostrar que la atención médica de los niños está mediada por los acuerdos y desacuerdos entre el padre, la madre y la familia extensa, situación que se torna más problemática cuando las mujeres sufren violencia de género.

Palabras clave: mortalidad infantil, desigualdad de género, violencia de género.

Abstract: The aim of this paper is to analyze how gender inequality affects the healthcare-seeking behavior of mothers with children under five years old who died of preventable causes in Ocotepec, Chiapas, during 2005-2010. A gender social constructionist-relational approach is used to demonstrate that the attention received by children is influenced by the level of agreement and or disagreement among the father, the mother and the extended family becoming more problematic when mothers suffer gender violence.

Keywords: infant mortality, gender inequality, gender violence.

Renata Gabriela Cortez Gómez. Doctora en Antropología por el Centro de Investigaciones y Estudios Superiores en Antropología Social, México. Temas de especialización: antropología médica; género, etnicidad y salud infantil. Correo electrónico: jatzobudano@ hotmail.com.
Enviado a dictamen: 20 de junio de 2016

Aprobación: 26 de abril de 2017.

Revisiones: 1. 


\section{Introducción}

L a mortalidad de menores de cinco años se considera un indicador de desarrollo económico (García-Chong et al, 2009). Desde hace décadas, en México se implementaron programas dirigidos a esta población con la finalidad de reducir la mortalidad (Sepúlveda et al., 2007), y se desarrollaron modelos de medición para conocer la magnitud del problema y sus determinantes con mayor precisión (Jiménez, 1992). Se sabe que los determinantes socioeconómicos inciden directamente, ya que la mortalidad de los niños muestra un comportamiento diferenciado en función de la clase social o el estrato socioeconómico (Jiménez, 1992), el origen étnico y el tipo de localidad (rural/urbana) en que habitan (García-Chong et al., 2009), la escolaridad de la madre (Sepúlveda et al., 2007), el gasto social en salud y el acceso a agua potable (López, Salvatierra y Nazar, 2010), entre otras variables que reflejan las desigualdades entre poblaciones o sectores de una población.

También se ha encontrado que, entre los sectores más desfavorecidos, las defunciones de niños tienden a acumularse en un reducido número de familias en las que la violencia intrafamiliar y el mal funcionamiento de las redes de apoyo son parte de su cotidianidad (Bronfman, 2000). Desde la antropología se ha enfatizado el papel de los saberes maternos en los procesos de enfermedad y muerte de población infantil tanto urbana, como rural e indígena (Osorio, 2001; Peña, 2007). Concretamente en poblaciones zoques de Chiapas, se ha estudiado el papel de las condiciones materiales de existencia y la migración en la nutrición infantil (Reyes, 1995).

Considerandoestos antecedentes, en miinvestigación doctoral (Cortez, 2015) me propuse analizar cómo los saberes maternos sobre los padecimientos infantiles, la desigualdad económica, la desigualdad de género y el funcionamiento de las redes de apoyo incidían en las trayectorias de atención de niños zoques que fallecieron por causas evitables en el periodo 2005-2010. En otro artículo abordo los dos primeros aspectos. La intención de éste es analizar el papel de la desigualdad de género, porque es un tema que no se ha estudiado en México. Ésta, si bien tiene como trasfondo la desigualdad socioeconómica de las familias zoques frente a la sociedad nacional, está determinada por normas comunitarias que subordinan a las mujeres y las hacen dependientes, por lo que restringen sus capacidades o recursos para atender a sus hijos. Esto demuestra la importancia de incluir la perspectiva de género en los trabajos sobre salud y muerte infantil.

\section{Género, salud y muerte}

El enfoque de género constructivista-relacional (Courtenay, 2000) sostiene que las relaciones de género son construcciones sociales producidas y reproducidas por hombres y mujeres a través de discursos y prácticas cotidianas que han aprendido y asimilado tempranamente, y sirven como filtro para interpretar la realidad social y genéricamente constituida (Connell, 2013). Las relaciones de género se articulan a otras esferas de la vida social como las relaciones económicas, simbólicas, de parentesco y de poder (Connell, 2013), y se han identificado tres instituciones que son importantes para su organización actual: el estado, el mercado de trabajo y la familia (Connell, 1993, en Courtenay, 2000).

Se ha demostrado que las representaciones y prácticas sobre lo considerado masculino y femenino, exponen a hombres y mujeres a riesgos diferenciales en determinados contextos, generando patrones diferenciados de morbi-mortalidad que no se explican por una vulnerabilidad biológica (Courtenay, 2000), por lo que el enfoque de género se ha vuelto indispensable en los trabajos sobre salud. Por ejemplo, se ha demostrado que una sobremortalidad de niñas en el estado de Punjab en la India se debe a que el sistema de parentesco (patrilineal) y de residencia (patrilocal) las excluye de la herencia. El nacimiento de una niña es poco deseable para sus padres, puesto que una vez que ella abandona el hogar paterno no contribuye al bienestar económico del mismo, de modo que cuando se enferma le procuran menos cuidados que a los niños varones (Das Gupta, 1987) 
En Latinoamérica es conocida la investigación sobre muertes de niños en la región del Pernambuco, Brasil, realizada por Scheper-Hughes (1997). Este trabajo reveló que el descuido selectivo era una forma de infanticidio que, por un lado, ocultaba la atención deficiente que recibían los niños en estado crítico; y, por otro lado, desplazaba la culpa al responsabilizarlo de su propia muerte debido a su constitución innata para afrontar la vida, lo que las madres evaluaban en función de la precocidad de su desarrollo, su dinamismo y verbosidad. Los niños que se mostraban callados, dóciles, pasivos, inactivos o lentos eran menos favorecidos en la crianza porque se percibían con pocas probabilidades de sobrevivir. La autora resaltó que el descuido selectivo tenía que vincularse directamente con las relaciones de explotación que empobrecían a los trabajadores de las favelas, más a las mujeres debido a su posición desigual ${ }^{1}$ frente a los hombres, pues en estas condiciones era difícil cubrir las necesidades básicas de los hijos. Por lo anterior, el descuido selectivo puede leerse desde una perspectiva de género.

En Chiapas se ha estudiado la relación entre mortalidad y género a partir del análisis de trayectorias de atención de mujeres tsotsiles y tseltales que murieron por causas obstétricas. En estas poblaciones, el estatus de la mujer se va definiendo desde niña y se va moldeando conforme se convierte en adulta; se ha comprobado que dicho estatus es definitivo para que su vida sea valorada y para que cuente con redes de apoyo en momentos críticos como el embarazo, el parto y el puerperio (Freyermuth, 2000). Sin embargo, hasta la fecha no se han realizado trabajos sobre género y muerte infantil.

\section{Ocotepec, Chiapas}

Ocotepec se ubica en la región serrana del norte del estado de Chiapas, se compone de 38 localidades y cuenta con 11878 habitantes, el 40\% de los cuales vive en la cabecera municipal (INEGI, 2013), donde realicé el trabajo de campo. El 82\% de la población habla zoque, ${ }^{2}$ de la que es monolingüe el 28\% (INEGI, 2011, 2013). Es considerado uno de los 125 municipios del país con menor índice de desarrollo humano, con el 94.7\% de su población en situación de pobreza ${ }^{3}$ (CONEVAL, 2012), pese a que el gobierno ha destinado presupuesto para mejorar servicios básicos, viviendas e incrementar infraestructura. ${ }^{4}$

En cuanto a las condiciones de salud de la población menor de cinco años, en el año 2010 la tasa de mortalidad de niños menores de cinco años (TMN) ${ }^{5}$ a nivel nacional era de 17 (The World Bank, 2015), mientras que la de Ocotepec era de 40.2 (CEIEG, 2014). Ese mismo año, al consultar las estadísticas de salud de la Unidad Médica Rural (UMR) de la cabecera municipal, encontré que el 27\% de los niños padecía desnutrición. Al consultar las bases de datos de mortalidad del Sistema Nacional de Información en Salud (SINAIS, 2012), encontré que las infecciones intestinales, la desnutrición, infecciones respiratorias y "fiebre" ocasionaban las tres cuartas partes de las muertes de niños ocotepecanos (ver cuadro 2). Lo que contrastaba con el panorama nacional, en el que la neumonía e influenza, infecciones intestinales, infecciones respiratorias y desnutrición en conjunto ocasionaban el $11 \%$ de las defunciones en 2010 (INEGI, 2016). Paulatinamente, las afecciones del periodo perinatal y las malformaciones congénitas están causando la mayoría de las muertes de menores de cinco años en México (ver cuadro l), mientras que en Ocotepec representan un $17 \%$ del total. Estos contrastes entre los perfiles de mortalidad y la TMN a nivel nacional y municipal sugieren que los niños ocotepecanos no están beneficiándose de las políticas públicas implementadas para abatir las muertes evitables, ${ }^{6}$ pues no son parte de la transición epidemiológica que vive su grupo de edad, por lo que es menester analizar qué elementos están coadyuvando a que fallezcan (ver cuadro 2).

\section{Metodología}

Esta investigación se planteó desde un enfoque cualitativo por el interés en recuperar el punto de vista de los actores, en el entendido de que lo que relatan es un recuerdo del que se precisan ciertos detalles y se olvidan otros, lo que es comprensible por el dolor que les causa y el tiempo que ha transcurrido 
(Freyermuth, 2000). Se empleó el método de estudio de casos instrumental con casos múltiples porque, sin perder de vista las especificidades de cada trayectoria de atención, permitía compararlas para desarrollar proposiciones empíricas de carácter general sobre la muerte infantil (Gundermann, 2008). En cada caso se utilizó la trayectoria de atención como una herramienta de indagación sobre lo que las familias hicieron desde que detectaron que el niño estaba enfermo y hasta que falleció. Este concepto se refiere a la secuencia de decisiones y estrategias que son instrumentadas por los sujetos para hacer frente a un episodio concreto del padecer; incluye la estructura de atención, enfermos, pacientes, terapeutas, otros mediadores, y todo tipo de recursos curativos y paliativos empleados por ellos (Osorio, 2001).

La unidad de análisis fue la familia, y no el grupo doméstico, ya que interesaba resaltar cómo el parentesco establecía formas de relación entre los géneros — de dependencia o independencia, armónicas o conflictivas-, aunque las personas no compartieran la residencia ni conformaran una unidad productiva (Salles y Tuirán, 1998). Estas relaciones determinarían la mayor o menor influencia de la familia extensa en las trayectorias de atención de los niños, y que funcionara o no como una red de apoyo. Los criterios de selección fueron: familias originarias y radicadas en Ocotepec al momento del trabajo de campo (junio 2012-julio 2013), que sufrieron la muerte de al menos un niño o niña menor de cinco años durante el periodo 2005-2010 por causas evitables, y que dieran su consentimiento para colaborar en la investigación. Elegí esta temporalidad para que la experiencia no fuera tan cercana y no produjera tanto malestar emocional a los padres. Sin embargo, pese al tiempo trascurrido, a algunos informantes se les dificultaba hablar y otros lloraban o guardaban silencio ante ciertas preguntas, por lo que decidí respetar su duelo a costa de algunas carencias de la investigación.

Las técnicas de obtención de información fueron: encuestas socioeconómicas y de salud reproductiva, y entrevistas semiestructuradas y a profundidad. También se empleó la observación participante de la dinámica familiar, y el cuidado y la atención de los cuadros patológicos que presentaron los niños. Además, recurrí a informantes secundarios como familiares cercanos de los informantes, así como a diez terapeutas locales: parteras, practicantes, y personal médico y de enfermería de la UMR. En total realicé 55 entrevistas a padres y familiares cercanos, lo que permitió reconstruir siete casos de defunción por causas evitables acaecidos en cinco familias. ${ }^{7}$ Además, realicé treinta entrevistas a terapeutas locales. La mitad de las veces se requirió apoyo de una traductora para hacer las entrevistas. Por cuestiones de espacio, en este artículo únicamente se recuperan dos casos en los que se ilustra brevemente el contexto familiar antes de la defunción y la trayectoria de atención.

La información se codificó y analizó desde la teoría fundamentada (Auerbach y Silverstain, 2003). Las categorías y subcategorías de análisis fueron: a) trayectorias de atención: representaciones sociales de las causas, y signos y síntomas de los padecimientos, duración, tratamientos empleados y terapeutas consultados; b) estatus de las mujeres: patrones de residencia y herencia, arreglos matrimoniales, mercado laboral y salarios femeninos, y transferencias económicas de Oportunidades. El estatus femenino dio cuenta del tipo de relación que establecieron con la pareja y otros miembros de la familia extensa, y cómo incidió en las trayectorias de atención de los niños (ver cuadro 3).

Sobre los informantes, en términos generales las mujeres tenían mayor escolaridad que los hombres, y sólo ellos realizaban actividades remuneradas. Ellos se unían siendo mayores y ellas siendo menores de edad, aunque los embarazos ocurrieron durante la mayoría de edad en la mayor parte de los casos. Todas las familias tenían ingresos bajos y las actividades económicas eran primarias en mayor medida. Sin embargo, la situación en dos de ellas era más precaria. La familia 4 se compensaba un poco con las transferencias de Oportunidades y las ayudas económicas que recibía del abuelo del niño. En cambio, la familia 5 no era beneficiaria de Oportunidades y tenía relaciones conflictivas con los hermanos del padre y la madre; durante el trabajo de campo fueron expulsados de la casa donde vivían, y 
la familia que los recibió no tardó en echarlos. Esto demuestra la importancia que en Ocotepec tiene contar con redes de apoyo significativas para subsistir (ver cuadro 4).

\section{Dos casos de defunción}

\section{Juan}

Nació el 5 de diciembre de 2007 y falleció el 14 de marzo de 2008 a los 3 meses de edad. La madre, Blanca, dice que murió de "tos"; en su acta de defunción se menciona "convulsiones" como la causa, la cual aparece en la base de datos del SINAIS. Este caso se reconstruyó con los testimonios de la madre y, en menor medida, de los abuelos maternos.

Blanca comentó que desde niña sufrió maltrato por parte de sus padres. Su madre le "gritaba" cuando quería llamarle la atención, y su padre le "pegaba con su faja" cuando consideraba que debía corregir su conducta. Esto impedía que confiara en ellos y les comunicara sus problemas. Antes de terminar la secundaria, un joven que desde hacía tiempo la "amenazaba" con agredirla si no aceptaba ser su pareja, abusó sexualmente de ella. Blanca "se quedó callada" por temor a que sus padres la reprendieran o quisieran casarla con él. Ella, que antes de esto deseaba "seguir estudiando", ya no quería ir a la escuela porque "tenía vergüenza" dado que pensaba que ese joven le comentaría a sus compañeros lo sucedido. Con esfuerzos concluyó la secundaria, pero al poco tiempo desertó del bachillerato.

Meses después, otro joven, originario de un municipio aledaño, fue a hablar con sus padres para "pedirla". Aunque el joven no era de su agrado, Blanca se fue con él porque pensó que ningún otro la haría su esposa al no ser "virgen". Al poco tiempo, ese hombre la abandonó y Blanca decidió irse a trabajar a Tuxtla Gutiérrez, donde conoció a otro joven que le pidió que fuera su mujer. Ella, "cansada de haber sufrido tanto", pensó que "era justo que fuera feliz" y aceptó. En una ocasión fue a Ocotepec de visita y le habló a su madre sobre su nueva pareja, pero ella le prohibió casarse porque el joven era de un municipio lejano y temía no volver a verla. Él fue a buscarla varias veces a Ocotepec, pero Blanca se sentía incapaz de dejar a sus padres. Él dejó de insistir y ya no la buscó. Aunque Blanca estaba embarazada, sus padres le dijeron que la apoyarían con la crianza de su bebé.

Juan tenía "tos", pero como "era su primer hijo y no tenía experiencia”, para Blanca este síntoma no representaba "gravedad". Ella dependía económicamente de su padre, quien le pidió que esperara unos días a que le pagaran su quincena para llevar a Juan con un terapeuta. Mientras tanto, la madre de Blanca consultó a un curandero que pasó por su casa. Éste dijo que Juan se había quedado "viendo para arriba", ${ }^{8}$ para curarlo utilizó seis velas, "popó de estrella" (una roca que se encuentra en la montaña) y huesos de zopilotes, pero no dio resultado. Juan lloraba mucho, así que Blanca fue a ver a otra curandera, que le dijo que la cama donde el niño dormía "estaba encantada" por los duendes;; había que hacerle varias curaciones, cada una de las cuales le costaría cien pesos. A la abuela le pareció un costo muy elevado, así que decidió curarlo ella misma; lo bañó con agua bendita y le dijo: "Que Dios te cuide y que Dios te bendiga porque tú no eres bautizado todavía". También regó la casa con agua bendita y le puso "hierbas en el pechito”. Esto tampoco lo curó. Ya había transcurrido una semana desde que Juan empezó a toser, y hasta entonces le pagaron al abuelo. Blanca lo llevó con un practicante $^{10}$ que le inyectó un medicamento, le puso supositorios y le recetó dos jarabes, uno de ellos era Ambroxol, para que "sacara la flema". Blanca dice que los jarabes "complicaron" el cuadro, "le dio como ataque, le salió calambre, empezó a temblar”; el bebé convulsionó varias veces esa noche, por lo que los abuelos decidieron suspender el tratamiento recetado por el practicante. Ella no sabía qué hacer, pero su padre le dijo que no se preocupara, que consultarían a otro terapeuta. Al día siguiente, los abuelos lo llevaron con un curandero que dijo que Juan "iba a morir, no se iba a componer", la causa era que en un sueño lo habían "maltratado" a causa de la "envidia" que le tenían por ser varón. El curandero regañó a los abuelos por no haber llevado a Blanca puesto que tenía que curarle el pecho; a Juan le hizo una limpia con sahumerio y hierbas, y recomendó 
a los abuelos que le hicieran otra con huevos de pato y pavo, pero tampoco se curó.

A la mañana siguiente, Blanca se fue sola a la clínica, dice que para entonces Juan "como que se hizo todo morado". El médico que lo atendió lo refirió al Hospital Regional de Tuxtla Gutiérrez, pero dudaba de que llegara porque estaba "bien grave". Blanca salió corriendo a su casa para preguntar a sus padres si la apoyarían económicamente con el traslado, ellos respondieron que sí, pero Juan murió minutos después.

Como digo, pues, que no tenía yo experiencia de nada. De ahíme dijo mi mamá queno me preocupara porque de todos modos me iba a pasar eso. [...] que sí, "ya lo sabía, nada más que no te dijimos porque te ibas a preocupar más, nos dijeron que de por sí iba a morir el niño, [...] le hicieron ese mal... no iba a quedar", me dijo, pero ya cuando pasó eso. Yo, la verdad, yo no creo mucho en eso, no creo. Yo digo porque diosito no quiso que mi bebé viniera a sufrir porque no tenía papá; tenía, nada más que mi mamá no quiso que yo vaya porque era lejos, y dijo mi mamá: "mejor no". Como cuatro veces me vino a buscar ese hombre y no quiso mi mamá, no quiso que yo me juntara con él. Por eso no fui y ya no lo busqué yo también. Y yo sí pensaba eso, "si llegara a quedar mi hijo, quieran o no quieran yo tengo que ir porque es responsabilidad de él (Blanca).

\section{Francisco}

Francisco nació el 25 de noviembre de 2005 y falleció el 20 de abril de 2008 en San Francisco Ocotal, ${ }^{11}$ cuando tenía dos años y cuatro meses de edad. De acuerdo con los padres, la causa de muerte fue "tos como tosferina"; el acta de defunción menciona que fue "bronquitis", y en la base de datos del SINAIS se señala "bronquitis aguda”. Este caso se reconstruyó con los testimonios de los padres y, en menor medida, de los tíos maternos.

Cuando era adolescente, la madre, Nidia, iba todas las tardes a San Francisco a visitar a Óscar, pero nadie en su familia lo sabía. Un día su hermano mayor "fue a traerla del pelo" porque no le parecía apropiado que saliera de casa sin avisar. Finalmente, un día ella "se huyó", se fue a vivir con Óscar. Su padre se enojó y la obligó a casarse por la Iglesia, pero al paso del tiempo la perdonó. Óscar no tenía qué ofrecerle, así que la llevó a vivir a casa de sus padres. La relación de Nidia con su suegra era conflictiva, con frecuencia discutían porque ésta le decía que: "comía mucho, que gastaba mucho dinero en comida y que era egoísta por no compartirle". Con el paso del tiempo Óscar construyó una casa en el mismo solar de sus padres, así que los conflictos siguieron, hasta que un día los expulsaron. Aunque Óscar defendía a Nidia del trato que le daba la suegra, a él no le gustaba que saliera de casa, y cuando recibía "su apoyo" [Oportunidades], compraba cien kilos de maíz "de una vez, para que ella ya no salga", pues pensaba que "no tiene nada qué salir a hacer" a la calle.

Francisco nació en casa de sus abuelos paternos. Conforme crecía y se desarrollaba fue presentando problemas de salud, como desnutrición y: "Cuando comía se le abultaba la pancita o se le inflamaba, y los pies los tenía chiquitos, la barriga se le inflaba cada que comía". Así fue como se dio cuenta de que su hijo estaba enfermo: "no le caía bien la comida. Además, le daba como un catarro en su garganta; que parecía que tenía dolor, le gritaba la garganta, chillaba, como si tuviera tos" (Nidia).

Preocupada por la salud de su hijo, Nidia lo llevó a consulta con unos médicos alópatas extranjeros que visitaban Ocotepec una vez por año. Estos médicos le dieron "pastillas y medicamentos", y le pidieron que llevara al niño con ellos todos los días durante un mes para que le dieran ciertos cuidados, a lo que ella aceptó. Nidia dijo que Francisco mejoró durante ese tiempo porque le dejó de "chillar la garganta", recuperó su peso y "se veía que iba a caminar". Los médicos ${ }^{12}$ propusieron llevárselo a Estados Unidos por un periodo de dos años para someterlo a otros tratamientos, pero Óscar no estuvo de acuerdo:

Ya los gringos lo iban a llevar y le iban a curar todo el cuerpo, pero dice que su esposo ya no lo quiso mandar, ella quería pero su esposo no, [...] [él dijo] "no, aunque me vean, no estoy viviendo muy jodido para 
que los gringos me digan que lo van a llevar mi hijo; voy a hacer todo lo posible para curar a mi hijo", por eso no lo quiso mandar. Y su papá le dijo: "mándalo, dáselo para que la criatura regrese buena y sana”, pero como su esposo le dijo no, ella sola ni puede. Toda la familia de ella la apoyaba pero la familia de su esposo le metió chisme para que no lo llevaran, le dijeron: "te van a decir, otra persona te está curando tu hijo" (traducción simultánea de la entrevista a Nidia).

Después, Francisco volvió a verse enfermo y esta vez Nidia y Óscar lo llevaron con un practicante de Ocotepec, quien dijo que "necesitaba fuerza y medicina". Durante un mes estuvieron llevando a Francisco con ese señor, que les dio pomadas, gotas y ampolletas. En total gastaron dos mil quinientos pesos, pero Francisco no caminaba y seguía presentando crisis de tos, fiebre y dificultades respiratorias. Nidia le reclamó a su esposo: "ese señor nada más te está engañando, es mentira lo que te está diciendo porque el niño no se está sanando".

Ella volvió a solicitar atención a los médicos extranjeros pero ellos respondieron: “ahora, como ya está más grave la criatura, ya no vamos a poder curar nosotros; tú no lo quisiste soltar cuando estaba chiquito". Ante la negativa, buscó otras alternativas, fue a Coapilla ${ }^{13}$ para ponerle veladoras a la virgen de Candelaria y pedirle que curara a su hijo; también llevó a Francisco y le pasó por el cuerpo palmas y flores santificadas. Asimismo, cada vez que a Francisco le daban las crisis de "tos, fiebre y no podía respirar", Nidia le ponía una vela a san Marcos, el santo patrón de Ocotepec. Ninguna de estas terapias dio resultado. Finalmente, una tarde volvió a presentar tos, "como tosferina o bronquitis", y murió a la mañana siguiente.

\section{Las dificultades de la atención}

Los casos presentados revelan los problemas de atención de los padecimientos infantiles en Ocotepec. Destaca el papel de los saberes maternos y de algunos terapeutas locales, que ya se han estudiado en otras regiones de México, demostrándose que las representaciones sociales sobre ciertos padecimientos en muchas ocasiones conducen al uso de recursos inapropiados o insuficientes para los cuadros clínicos que se presentan (Freyermuth, 2000; Peña, 2007); también pueden causar iatrogenias (Osorio, 2001) o impedir el reconocimiento de problemas de salud como la desnutrición severa (Reyes, 1995).

Estos saberes, en el caso de Juan, impidieron el reconocimiento de un cuadro de neumonía severa, lo que sabemos por los signos que presentaba: fiebre, tos, dificultad respiratoria, convulsiones e insuficiencia respiratoria. También impidieron un tratamiento apropiado, que habría implicado el uso de un antibiótico, pues se emplearon terapias tradicionales que facilitaron la evolución natural de la infección respiratoria aguda. Transcurrió al menos una semana hasta que Juan recibió un antibiótico (la ampolleta), un antipirético (los supositorios) y un expectorante (Ambroxol), pero al parecer era tarde para aplicar tal terapia pues su estado era crítico, lo que sabemos por las convulsiones. A esas alturas requería hospitalización, pero el practicante no sugirió su traslado a un hospital. Más tarde, los abuelos atribuyeron el empeoramiento de su salud a una iatrogenia cometida por el practicante, lo que los llevó a suspender el tratamiento y a esperar horas para buscar atención. El siguiente terapeuta consultado fue otro curandero que, si bien detectó que el estado del bebé era grave, aplicó más terapias inapropiadas y tampoco sugirió su hospitalización. Cuando Juan llegó a la clínica local, era tarde para realizar su traslado al hospital.

El caso de Francisco no apunta específicamente a una defunción causada por infección respiratoria aguda, sino por la convergencia de varios problemas de salud, entre ellos desnutrición severa, lo que explicaría que algunos alimentos le sentaran mal y que presentara retraso en su desarrollo, lo que se sabe porque no había comenzado a caminar en el momento que los padres consideraban normal. Otro problema fue que durante varios meses sufrió crisis de tos, dificultad respiratoria y fiebre. La literatura médica subraya que los niños que sufren desnutrición son proclives a las infecciones respiratorias debido a que su sistema inmunológico se 
encuentra deteriorado. Esto explicaría la recurrencia de las crisis de Francisco. Otra explicación es que hubiera sufrido otra patología no reconocida ni por los padres ni por el practicante dado que nunca se atendió apropiadamente, lo que hace comprensible la oferta de los médicos extranjeros de proporcionarle tratamiento fuera del país.

Al no reconocimiento de los respectivos problemas de salud de los niños y las deficiencias de la atención médica proporcionada, que también observamos en los demás casos de defunción reconstruidos, habría que sumar la situación económica de las familias, que en el caso de Juan retrasó la atención por una semana, hasta que le pagaron al abuelo. En el caso de Francisco, no se precisan dificultades económicas puntuales, pero es evidente que el gasto que sus padres realizaron con el practicante fue excesivo para su nivel de ingresos. La mercantilización de las prácticas médicas en Ocotepec, que también se ha observado en otros contextos (Osorio, 2001; Peña, 2007), obstruye la atención porque la hace dependiente de la capacidad de pago de las familias. Si éstas con frecuencia no tienen dinero en efectivo ni redes de apoyo que les hagan préstamos, es altamente probable que la atención se retrase o definitivamente se vea impedida. Esto también afecta el traslado a los hospitales (Freyermuth, 2000; Osorio, 2001), que generalmente se encuentran distantes. Estos problemas los trato en otro artículo y los desarrollo en mi tesis doctoral, pero era importante señalarlos puesto que en los demás casos de defunción también fueron determinantes.

\section{Vida social en Ocotepec y el papel de las mujeres}

A continuación analizaré el papel que ha jugado la desigualdad de género. Para comenzar, describiré cuatro aspectos de la vida social ocotepecana que determinan el estatus de las mujeres.

\section{Los patrones de residencia y herencia}

En Ocotepec, el patrón de herencia es patrilineal, como era a principios del siglo XX (Báez- Jorge, 1990), pero la residencia puede ser neolocal o patrilocal. La neolocalidad, que se refiere a que la residencia del nuevo matrimonio se establece en un lugar diferente al de las familias de origen, ha incidido en un menor control económico por parte de éstas, pero no ha mejorado el estatus de las mujeres porque la "costumbre" dicta que los hijos varones, principalmente el mayor, reciban herencia. Las mujeres la reciben sólo en casos muy puntuales, por ejemplo, cuando no hay hijos varones o cuando ella se hace cargo de los padres.

\section{Los arreglos matrimoniales}

Hasta hace unas décadas, los matrimonios los concertaban los padres de la pareja. La familia del novio realizaba el pago de la novia — con maíz, aguardiente, frijol, chocolate - o de la boda, que se realizaba después de una serie de visitas que el "embajador o costumbrero" - autoridad religiosa - junto con el joven y su padre, hacían a los padres de la futura desposada (Báez-Jorge, 1990). A partir de mis observaciones puedo decir que en la actualidad existen formas diversas de llevar a cabo las uniones, y éstas dependen del estatus socioeconómico del futuro esposo. Los jóvenes que cuentan con algún capital económico, sea en bienes heredados o adquiridos con su trabajo, y que son respetuosos de las costumbres, realizan la petición de la novia por respeto a los padres de ésta, aunque la decisión la toma la pareja, que por lo general ha tenido tiempo para conocerse. La presencia del "costumbrero" ya no es necesaria, como tampoco el pago. Los jóvenes que no cuentan con suficiente o ningún capital económico recurren al rapto; en este caso se dice que la pareja "se huyó" o que "se huyeron". El rapto puede ser negativo para ambos ya que el hecho de no comunicar a los padres la decisión de formar una pareja puede generar conflictos o alejamientos.

\section{El mercado laboral y los salarios femeninos}

El trabajo femenino se valora menos que el masculino en Ocotepec. ${ }^{14}$ Esta es una razón para que las informantes no recurran al trabajo asalariado, ya que la ganancia no compensa el "descuido" de sus hijos; otra razón es que 
el trabajo femenino todavía es mal visto. Durante el trabajo de campo recuperamos testimonios de mujeres que eran acusadas de "tener amantes", o eran señaladas como "prostitutas" o "alcohólicas" cuando vivían fuera de la localidad o pasaban tiempo fuera de su casa, principalmente por motivos laborales.

\section{Las transferencias económicas de Oportunidades ${ }^{15}$}

Si bien este programa pretende contrarrestar la dependencia económica de las mujeres, en Ocotepec estos ingresos no gozan del mismo reconocimiento que los de los esposos. Aunque con estos también se pagaban deudas y gastos escolares, de salud, alimentación y viajes, las mujeres reconocían al esposo como el proveedor. Quizás esto se deba a que los ocotepecanos diferencian bien los componentes de las transferencias de Oportunidades los padres dicen que "con el dinero de mis hijos se compró tal cosa"; a su vez, las niñas y los niños, y mucho más los y las jóvenes, les piden a sus padres que les compren talo cual cosa con "su dinero" o "su beca"-, lo que evita que se reconozcan como aportaciones femeninas.

Estos aspectos demuestran que la posición de las mujeres frente a los hombres sigue siendo asimétrica, lo que las hace dependientes de sus esposos. Sin embargo, la situación puede ser aún más desventajosa. En estas familias observé tres patrones:

1. Las mujeres (Natividad y Lucía) que decidieron casarse con jóvenes originarios de la misma localidad, con los que tenían poca diferencia de edad, que gozaron de la anuencia de sus respectivas familias, por lo que ellos recibieron una herencia sólida. La residencia de estas parejas era neolocal.

2. Las mujeres (Brígida y Blanca) que fueron dadas en matrimonio por sus padres, estuvieran ellas o no de acuerdo; sus esposos no recibieron herencia, por lo que su residencia fue patrilocal durante algunos años. Una de ellas fue abandonada por su pareja.

3. Las mujeres (Nidia, Julia y Blanca) que "se huyeron" o se unieron con hombres originarios de localidades o municipios distintos, lo que les causó conflictos con sus familias; sus esposos tampoco recibieron herencia, por lo que su residencia era patrilocal. A una de ellas (Blanca) la obligaron a separarse de su pareja.

En las familias con residencia neolocal se observó que la pareja tenía una convivencia armónica y que tenían redes de apoyo sólidas; éstas sufrieron la muerte de un hijo. En cambio, en las familias con residencia patrilocal se observó que las mujeres sufrían violencia por parte del esposo u otras mujeres - la suegra, la propia madre, la cuñada-, y que sus redes de apoyo eran débiles o inexistentes; estas familias sufrieron la muerte de dos hijos. Es decir, las mujeres que tenían una posición aún más asimétrica sufrían violencia.

La violencia en el entorno doméstico es un fenómeno complejo cuyas raíces se encuentran en las desigualdades de género que producen diferenciales de poder entre mujeres y hombres. Por esta razón no se puede pensar en atacar el problema sin confrontar las normas culturales y las estructuras sociales que perpetúan la desigualdad entre hombres y mujeres y la construcción de identidades de género autoexcluyentes y jerarquizadas (Saucedo, 2000: 79).

Debido al espacio no ha sido posible describir las historias de todas las familias, y únicamente se han señalado algunos elementos que demuestran que dos informantes sufrieron violencia emocional, física y sexual desde que eran solteras, las dos primeras estaban justificadas porque eran mecanismos para corregir su comportamiento. Freyermuth (2000) encontró formas de corrección parecidas dirigidas a mujeres tsotsiles y tseltales, que continuaban después del matrimonio y las hacían víctimas de violencia doméstica, lo que obstruía su atención médica por causas obstétricas y coadyuvaba a que fallecieran.

La violencia es un problema frecuente para las mujeres indígenas chiapanecas. La Encuesta Nacional sobre la Dinámica de las Relaciones en los Hogares 2011 reveló que el 28.4\% de las mujeres chiapanecas 
hablantes de lengua indígena que estaban unidas o solteras habían sido violentadas por su pareja. El 91.5\% de ellas sufrió violencia emocional "que consiste en actos u omisiones que se expresan a través de prohibiciones, condicionamientos, amenazas, insultos, burlas y gestos agresivos" (INEGI, 2014: 28). El 36.1\% sufrió violencia física, que se expresa en un empujón o bofetada, hasta lesiones que podrían causar su muerte, y el 26.2\% sufrió violencia económica, "que suele presentarse desde la omisión de las necesidades más básicas de una familia: alimentación, salud, educación, hasta el robo, destrucción y actos fraudulentos de los bienes familiares por parte del cónyuge" (INEGI, 2014: 12). El 12.6\% sufrió violencia sexual, que comprende "el contacto abusivo, la presión para que participe en un acto sexual en contra de su voluntad y la tentativa o consumación de tales actos" (INEGI, 2014: 5). Aunque la encuesta limita la violencia doméstica a la ejercida por la pareja, lo que invisibiliza la violencia ejercida por otros familiares, demuestra que este problema es grave y requiere atención.

En el caso de Blanca, la violencia emocional y física evitó que hubiera buena comunicación y una relación de confianza con sus padres, por lo que cuando sufrió violencia sexual, lejos de denunciar al agresor, se quedó callada. La pérdida de su virginidad le quitó su valor como mujer, lo que anuló su proyecto de vida y la orilló a unirse a un hombre que no escogió. Después de que éste la abandonara, se unió a otro chico que sí le agradaba, pero su madre la forzó a separarse; es decir, volvió a sufrir violencia emocional. Siendo madre soltera, se hizo dependiente de sus padres, lo que retrasó la atención de Juan porque el abuelo no tenía dinero; su posición subordinada, oculta en su "falta de experiencia", le impidió exigirle a su padre que le diera el dinero pronto y la desplazó de su lugar de madre, ${ }^{16}$ por lo que fueron los abuelos quienes tomaron las decisiones sobre la atención de Juan y le ocultaron su inminente defunción. Su testimonio indica que, pese a vivir con sus padres, se sentía incapaz de afrontar la enfermedad de su bebé porque su estatus era desigual, y tampoco tenía a quién solicitarle un préstamo debido a su incapacidad para pagarlo por su cuenta.
Nidia, una vez que se casó, siguió sufriendo violencia física por parte de Óscar, que no quería que saliera de casa, y violencia emocional por parte de su suegra y otros miembros de la familia de su compañero, quienes le dijeron a éste que la gente hablaría mal de él por no ser capaz de curar a su hijo por sus propios medios. Esto impidió que Francisco recibiera atención médica especializada fuera del país, por lo que quedó a merced de los recursos locales que sí aprobaba el padre, pero que eran insuficientes o inapropiados. En los demás casos de defunción, que por falta de espacio no presenté, se apreciaban problemas similares en las trayectorias de atención debido a la subordinación femenina y a la violencia que sufrían.

Los casos analizados demuestran que, si bien la desigualdad de género no es causa única o directa de muerte, es un problema que determina el tipo de relación que se establece entre los miembros de la familia extensa y, por tanto, determina las decisiones en las trayectorias de atención, principalmente cuando se comparte la residencia. Estas mujeres eran totalmente dependientes cuando sus hijos enfermaron, por lo que sus opciones "reales" o asequibles de atención médica eran limitadas; pero además eran víctimas de violencia física y emocional, lo que las hizo subordinarse ante las decisiones de otros. Ellas sufrieron violencia desde niñas, y siguieron sufriéndola por parte de sus parejas u otras mujeres de la familia, por eso no pueden romper con ella, porque se sostienen a partir de normas sociales que las hacen dependientes de aquellos que las violentan. Esto las hizo vulnerables a ellas y a sus hijos.

\section{Consideraciones finales}

Pese a las políticas públicas diseñadas para evitar la muerte de niños menores de cinco años en México, en ciertos municipios sigue siendo un problema. En este trabajo se ha señalado que en Ocotepec los saberes maternos y de los terapeutas locales determinan una atención médica deficiente o insuficiente. Asimismo, se ha demostrado que la economía de las familias obstruye la atención porque con frecuencia no tienen dinero para pagar a los terapeutas locales o los traslados a 
los hospitales. No obstante, la desigualdad de género también incide negativamente en la atención médica de los niños.

El estatus de las mujeres en Ocotepec es desigual respecto al de los hombres debido a que las instituciones sociales las hacen dependientes de ellos. Con frecuencia también sufren violencia emocional y física desde que son solteras. Con el matrimonio su estatus no siempre mejora; por el contrario, puede subordinarlas aún más cuando la unión se realiza sin su consentimiento o el de sus padres, y la residencia es patrilocal. Este último hecho incrementa las probabilidades de que las relaciones con su pareja y las familias de ambos sean negativas, y también las lleva a sufrir violencia. La violencia emocional y física se sostiene de discursos y prácticas culturales legítimas, aprobadas por la familia y la comunidad, y es ejercida por quienes son responsables de su manutención o deberían funcionar como sus redes de apoyo, lo que impide que puedan escapar de la violencia.

En Ocotepec, la subordinación de las mujeres obstruye la atención médica de sus hijos porque a ellas no se les permite decidir, sino que las decisiones las toman otros miembros de la familia, por lo que la atención termina siendo tardía, inapropiada o insuficiente. La desigualdad de género es uno de los elementos que coadyuva a la muerte de los niños, pues actúa sinérgicamente con los saberes maternos y los problemas económicos. En consecuencia, las políticas públicas orientadas a mejorar la salud y la sobrevivencia infantil tendrían que acompañarse de estrategias contra la desigualdad de género, así como con intervenciones específicas para prevenir, denunciar y erradicar la violencia de género.

\section{Notas}

${ }^{1}$ De acuerdo con la autora, las mujeres recibían salarios inferiores a los de sus congéneres, por lo que tenían que trabajar más horas que ellos para incrementar sus ingresos, lo que les causaba violencia doméstica y abandono de la pareja, puesto que el trabajo femenino era una afrenta a la capacidad masculina de proveer, y las obligaba a ausentarse más tiempo del hogar, por lo que desatendían a sus hijos.

${ }^{2}$ En Chiapas hay 57075 hablantes de lengua zoque que representan el 5\% de la población indígena del estado, ya que el zoque es la lengua que muestra una mayor tendencia a ser sustituida por el español.

${ }^{3}$ La pobreza se define como no disponer de ingresos suficientes para comprar la canasta alimentaria y no alimentaria, además de al menos una carencia social que puede ser: a) rezago educativo; b) acceso a los servicios de salud; c) acceso a la seguridad social; d) calidad y espacios en la vivienda; e) acceso a los servicios básicos en la vivienda, y f) acceso a la alimentación.

${ }^{4}$ Esto se ha realizado a través del Programa de los 28 Municipios con Menor Índice de Desarrollo Humano (28 MMIDH) (sexenio 2006-2012), y el Plan Nacional de Zonas Deprimidas (sexenio 2013-2018).

${ }^{5}$ TMN: es la tasa de mortalidad de niños menores de cinco años. Se refiere a las probabilidades de morir de un recién nacido antes de cumplir los cinco años y se estima en función de mil nacidos vivos.

${ }^{6}$ Estas políticas incluyen la distribución de Sales de Rehidratación Oral (SRO), las Semanas Nacionales de Vacunación, los programas de Prevención, diagnóstico y tratamiento de enfermedad diarreica e infección respiratoria aguda y Prevención de la desnutrición, el programa Agua Limpia, Oportunidades, entre otros.

${ }^{7}$ Estas cinco familias vieron morir a ocho niños durante el periodo 2005-2010, pero no fue posible reconstruir uno de los casos debido a que los padres ya no recordaban detalles del evento.

8 "Quedar mirando fijamente", o "viendo para arriba" es un padecimiento infantil reconocido por los terapeutas y las madres ocotepecanas. Afecta a menores de un año y se debe a que la vista del bebé se fija en objetos o luces que llaman su atención, pero una vez que el estímulo desaparece, el bebé se queda con la vista fija en un punto. Para que los ojos recuperen su movimiento normal, hay que aplicar terapias.

${ }^{9}$ Los terapeutas y las mujeres ocotepecanas refirieron que las enfermedades son causadas por agentes naturales (como el clima, la falta de higiene y la acción humana), y sobrenaturales (como los duendes, los 
dueños del agua y del monte, etc.). Los primeros causan enfermedades naturales (diarrea, tos, cáncer, gastritis, hipertensión, colesterol, estreñimiento, antojo, ojo, carga, caída de mollera, "mirar fijamente", etc.), y los segundos enfermedades "hechas" (encanto, susto, brujería, envidia, etc.). Las enfermedades naturales son consideradas "chicas" ya que si se atienden oportuna y adecuadamente, se curan. Sin embargo, si no "se atienden bien" pueden volverse "grandes", es decir, complicarse y cobrar la vida de la persona. Hay enfermedades que son consideradas "grandes" desde su inicio, como la mayoría de las enfermedades "hechas" (como el encanto, susto, brujería), y otras naturales (como el cáncer, el ojo y el antojo).

${ }^{10}$ Los practicantes son terapeutas ocotepecanos que tienen conocimientos de medicina tradicional pero colaboraron como auxiliares de salud de la UMR de Ocotepec durante algunos años, después de los cuales abrieron sus propios consultorios privados. La mayor parte de sus recursos curativos son alópatas, aunque también utilizan medicina naturista, pues consideran que los tradicionales no son efectivos para muchos de los padecimientos que atienden, principalmente enfermedades diarreicas, infecciones de las vías respiratorias, parasitosis, gastritis, colitis, hipertensión, diabetes, dolores en diferentes partes del cuerpo, curaciones de heridas, etc. Sin embargo, ellos respetan a los especialistas de la medicina tradicional que atienden padecimientos no reconocidos por la medicina alópata.

"Localidad de Ocotepec, situada a escasos cinco kilómetros de la cabecera.

${ }^{12}$ Estos médicos eran voluntarios de una ONG que, de forma gratuita, una o dos veces por año proporcionaba atención médica dental, consultas de medicina general, medicamentos y capacitaciones a parteras en Ocotepec. Anteriormente habían solicitado a los padres de un niño ocotepecano que sufría de pie equino, que les cedieran los derechos para llevarlo a Estados Unidos y darle el tratamiento que requería (cirugías y rehabilitación). Este niño vivió siete años en el extranjero, y sólo regresaba a Ocotepec de vacaciones. Hecho un joven, volvió a Ocotepec con su familia. Él y su familia siguen teniendo una relación estrecha con los miembros de la
ONG, que siguen trabajando en este municipio pero con recursos más limitados.

${ }^{13}$ Municipio colindante con Ocotepec.

${ }^{14}$ Mientras que un jornalero gana $\$ 70.00$ y un albañil $\$ 100.00$ diarios, las mujeres que trabajan como empleadas domésticas o dependientas en las tiendas perciben no más de $\$ 50.00$ diarios o $\$ 1000.00$ al mes.

${ }^{15}$ El Programa de Desarrollo Humano Oportunidades (2000-2012) es federal y fue diseñado para intervenir en tres de las áreas de la vida de la población que se ven más afectadas por la pobreza: salud, educación y alimentación, sobre las cuales se dirigen acciones coordinadas con la entrega de recurso en efectivo (las transferencias monetarias conocidas como "becas"). En el sexenio actual cambió nombre por Prospera.

${ }^{16}$ En 2012 otro hijo de Blanca enfermó de neumonía a los quince días de nacido. Su madre le aconsejó que se quedara en Ocotepec, pero Blanca decidió viajar a Tuxtla Gutiérrez para solicitar atención en el Hospital Regional, donde el bebé permaneció hospitalizado durante 15 días. $\mathrm{Su}$ esposo obtuvo un préstamo para pagar la atención. Esta, junto a otras trayectorias de atención que observé durante el trabajo de campo, demostraron que, con una pareja que responda por ella, Blanca se siente capaz de buscar atención para sus hijos. Hoy día, ella elige a los terapeutas que considera eficaces, aunque su madre opine lo contrario. Y si no tiene dinero, solicita préstamos que luego su esposo tiene que liquidar.

\section{Referencias bibliográficas}

Auerbach, Carl F. y Louise B. Silverstain (2003). Qualitative Data, An Introduction to Coding and Analysis. Nueva York: New York University Press.

Báez-Jorge, Félix (1990). "La mujer zoque. Pasado y presente". En Alfonso Villa-Rojas et al., Los zoques de Chiapas. México: CONACULTA, INI, pp. 237-259.

Bronfman, Mario (2000). Como se vive se muere. Familia, redes sociales y muerte infantil. Cuernavaca: CRIM-UNAM.

CEIEG (Comité Estatal de Información Estadística y Geográfica de Chiapas) (2014). Perfiles municipales: Ocotepec. Disponible en: http://www.ceieg.chiapas. gob.mx/home/ (consultado el 15 de enero de 2015). 
CONEVAL (Consejo Nacional de Evaluación de la Política de Desarrollo Social) (2012). Informe de pobreza en México: el país, los estados y sus municipios 2010. México: CONEVAL.

Connell, Raewyn (2013). "Género, salud y teoría: conceptualizando el tema en perspectiva mundial y local". En Nómadas, 39: 63-77.

Cortez Gómez, Renata Gabriela (2015). "Muerte de niños menores de cinco años, Desigualdad étnica, económica y de género como condicionantes de la autoatención en familias zoques". Tesis de doctorado. Centro de Investigaciones y Estudios Superiores en Antropología Social, México.

Courtenay, Will H. (2000). "Constructions of masculinity and their influence on men's well-being: a theory of gender and health". En Social Science and Medicine, 50: 1385-1401.

Das Gupta, Monica (1987). "Selective Discrimination against Female Children in Rural Punjab, India”. En Population and Development Review, 13(1): 77-100.

Freyermuth Enciso, María Graciela (2000). Chenalhó. Género, etnia y generación. Factores constitutivos del riesgo durante la maternidad. Tesis de doctorado. Universidad Nacional Autónoma de México, México.

García-Chong, Néstor Rodolfo, Laura Elena Trujillo Olvera, Marlene Zúñiga Cabrera, Benito Salvatierra Izaba y Austreberta Nazar Beultespacher (2009). "Políticas económicas y supervivencia infantil en México, Centroamérica y el Caribe". Ponencia presentada en el VII Congreso de la Asociación Mexicana de Estudios Rurales A.C., San Cristóbal de Las Casas, México.

INEGI (Instituto Nacional de Estadística, Geografía e Informática) (2011). Principales resultados del Censo de Poblacióny Vivienda 2010, Chiapas. México: INEGI.

INEGI (2013). Panorama sociodemográfico de los 125 municipios con menor IDH. México: INEGI.

INEGI (2014). Panorama de Violencia contra las Mujeres en Chiapas, ENDIREH 2011. México: INEGI.

INEGI (2016). Principales causas de mortalidad por residencia habitual, grupos de edad y sexo del fallecido, Consulta de resultados: tabulados básicos. Disponible en: http:// www.inegi.org.mx/est/contenidos/proyectos/registros/
vitales/mortalidad/tabulados/ConsultaMortalidad.asp (consultado el 20 de marzo de 2016).

Jiménez Ornelas, René A. (1992). Procesos de mortalidad en menores de cinco años: Factores sociales, económicos y demográficos más directamente asociados en dos estratos sociales del estado de Guanajuato. Tesis de doctorado. El Colegio de México, México.

Gundermann Kröll, Hans (2008). "El método de los estudios de caso". En María Luisa Tarrés (comp.), Observar, escuchar y comprender. Sobre la tradición cualitativa en la investigación social. México: COLMEX, FLACSO, Porrúa, pp. 25l-288.

López González, Olga Lidia, Benito Salvatierra Izaba y Austreberta Nazar Beutlespacher (2010). "Desigualdad socioeconómica y salud en la niñez en América Latina y la frontera sur de México". Ponencia presentada en el II Congreso Latinoamericano y Caribeño de Ciencias Sociales, Ciudad de México, México.

Osorio Carranza, Rosa María (2001). Entender y atender la enfermedad: Los saberes maternos frente a los padecimientos infantiles. México: INI, INAH, CIESAS.

Peña Ruiz, Patricia Magdalena (2007). Mortalidad infantil y brujería. El caso de la etnia mazahua. Tesis de doctorado. Universitat Rovira I Virgili, Catalunya, España.

Reyes Gómez, Laureano (1995). “Antropología de un volcán, Migración y nutrición de comunidades zoques, a diez años de la erupción del Chichonal". Tesis de maestría. Escuela Nacional de Antropología e Historia, México.

Salles, Vania y Rodolfo Tuirán (1998). "Cambios demográficos y socioculturales: familias contemporáneas en México". En Beatriz Schmukler (coord.), Familias y relaciones de género en transformación. México: EDAMEX, Population Council, pp. 83-126.

Saucedo González, Irma (2000). "El proceso para hacer visible la violencia doméstica en México". En Alicia Gil Gómez y Dora Sales Salvador (eds.), Mujeres. Mediar para repensar las relaciones con "lo otro". S.l.: Fondo Social Europeo, Proyecto NOW, Universidad Jaume I, pp. 69-72.

Scheper-Hughes, Nancy (1997). La muerte sin llanto, Violencia y vida cotidiana en Brasil. España: Ariel. 
Sepúlveda, Jaime et al. (2007). "Aumento de la sobrevida en menores de cinco años en México: la estrategia diagonal". En Salud Pública de México, 49, sup. 1: 110-125. SINAIS (Sistema Nacional de Información en Salud) (2012). Mortalidad, información tabular. Disponible en http://sinais.salud.gob.mx/mortalidad/ (consultado el 8 de enero de 2012).

The World Bank (2015). Mortality rate, under-5 (per 1,000). Disponible en: http://data.worldbank.org/indicator/ SH.DYN.MORT (consultado el 26 de agosto de 2016). 
Cuadro 1. Causas de defunción de la población menor de cinco años, Ocotepec, Chiapas, periodo 2005-2010

\begin{tabular}{lcc}
\hline \multicolumn{1}{c}{ Causa de defunción } & Número de defunciones & Porcentaje \\
\hline Infecciones infecciosas intestinales & 29 & 23 \\
Desnutrición proteico-calórica & 27 & 22 \\
Infecciones respiratorias & 23 & 19 \\
Afecciones del periodo perinatal & 17 & 14 \\
“Fiebre” & 13 & 10 \\
Trastornos de la piel & 5 & 4 \\
Enfermedades congénitas & 4 & 3 \\
Anemia & 2 & 2 \\
Otras & 4 & 3 \\
Total & 124 & 100 \\
\hline
\end{tabular}

Fuente: Bases de datos de mortalidad del Sistema Nacional de Información en Salud, 2005-2010. Recuperado de http://sinais. salud.gob. $\mathrm{mx} / \mathrm{mortalidad} /$.

Cuadro 2. Principales causas de defunción de la población menor de cinco años, México, 2010

\begin{tabular}{lcc}
\hline \multicolumn{1}{c}{ Causa de defunción } & Número de defunciones & Porcentaje \\
\hline Afecciones del periodo perinatal & 14377 & 42 \\
Malformaciones congénitas & 7330 & 21 \\
Neumonía e influenza & 1653 & 5 \\
Enfermedades infecciosas & 852 & 2 \\
intestinales & 768 & 2 \\
Accidentes & 664 & 2 \\
Infecciones respiratorias agudas & 621 & 2 \\
Desnutrición & 8251 & 24 \\
Resto de las causas & 34516 & 100 \\
Total &
\end{tabular}

Fuente: Principales causas de mortalidad por residencia habitual, grupos de edad y sexo del fallecido (INEGI, 2016). 
Cuadro 3. Datos sociodemográficos de las informantes

\begin{tabular}{|c|c|c|c|c|c|c|}
\hline Familia & 1 & 2 & 3 & 4 & 5 & \\
\hline Nombre & Brígida & Blanca & Natividad & Lucía & Nidia & Julia \\
\hline Edad & 40 & 22 & 31 & 31 & 27 & 36 \\
\hline Escolaridad & $4^{\circ}$ primaria & $\begin{array}{l}\text { Secundaria } \\
\text { completa }\end{array}$ & $4^{\circ}$ primaria & $4^{\circ}$ primaria & $5^{\circ}$ primaria & Ninguna \\
\hline $\begin{array}{l}\text { Edad matrimonio/ } \\
\text { unión }\end{array}$ & 14 & 16 & 19 & 16 & 16 & 20 \\
\hline $\begin{array}{l}\text { Edad primer } \\
\text { embarazo }\end{array}$ & 18 & 16 & 21 & 18 & 18 & 23 \\
\hline No. embarazos & 7 & 3 & 5 & 3 & 5 & 7 \\
\hline Muertes perinatales & & & & & 1 & \\
\hline Muertes infantiles & & 1 & & 1 & & 1 \\
\hline $\begin{array}{l}\text { Muertes } \\
\text { preescolares }\end{array}$ & 1 & & 1 & & 1 & 1 \\
\hline $\begin{array}{l}\text { Edades de los hijos } \\
\text { y posición de los } \\
\text { fallecidos }\end{array}$ & $\begin{array}{l}22,18,15 \\
13,(+), 7,4\end{array}$ & $(\dagger), 3,2$ & $10,(\dagger), 6,3,1$ & 13, 11, (†) & $\begin{array}{c}9,(\dagger), 3,2, \\
(\dagger)\end{array}$ & $\begin{array}{c}\text { 13, 10, (†), 6, } \\
(\dagger), 1\end{array}$ \\
\hline $\begin{array}{l}\text { Total defunciones } \\
\text { de menores de } \\
\text { cinco años }\end{array}$ & 1 & 1 & 1 & 1 & 2 & 2 \\
\hline
\end{tabular}

Fuente: Encuestas sociodemográficas, Ocotepec, Chiapas, junio de 2012- agosto de 2013.

Los datos de este cuadro corresponden al periodo de trabajo de campo. Sobre la familia 1: Blanca es hija de Brígida.

\section{Cuadro 4. Datos socioeconómicos de los informantes}

\begin{tabular}{lcccccc}
\hline \multicolumn{1}{c}{ Familia } & 1 & 2 & 3 & 4 & 5 & \\
\hline Nombre & Urbano & Daniel* & Alfonso & Pablo & Óscar & Elías \\
Escolaridad & Ninguna & No disponible & $5^{\circ}$ primaria & $2^{\circ}$ primaria & $2^{\circ}$ primaria & Ninguna \\
$\begin{array}{l}\text { Actividad económica } \\
\text { principal }\end{array}$ & Peón & Albañil & Agricultor & Agricultor & Jornalero & Jornalero \\
$\begin{array}{l}\text { Actividad económica } \\
\text { secundaria }\end{array}$ & Agricultor & & Albañil & Músico & & \\
$\begin{array}{l}\text { Ingreso mensual } \\
\text { promedio }\end{array}$ & 2000.00 & 3000.00 & 1500.00 & 1000.00 & 700.00 & 600.00 \\
\hline
\end{tabular}

Fuente: Encuestas socioeconómicas, Ocotepec, Chiapas, junio de 2012- agosto de 2013.

* Estos datos corresponden al momento del trabajo de campo, para entonces Blanca (Familia 1) ya se había unido a Daniel, con quien tiene dos hijos. La pareja vivía en casa de los padres de Blanca, aunque era una unidad productiva diferenciada ya que sus gastos y alimentos, entre otros recursos, no los compartían. 